\title{
IMPACTO ECONÓMICO SOBRE EL REGADÍO DEL VINALOPÓ-ALACANTÍ DE LA SUSTITUCIÓN DE EXTRACCIONES SUBTERRÁNEAS POR RECURSOS DEL TRASVASE JÚCAR-VINALOPÓ
}

\author{
$\underline{\text { Javier Calatrava }}^{a *}$, David Martínez-Granados ${ }^{a}$ y Vicente José Richart ${ }^{b}$
}

${ }^{a}$ Escuela Técnica Superior de Ingeniería Agronómica, Universidad Politécnica de Cartagena (Cartagena, Murcia; j.calatrava@upct.es, david.martinez@upct.es). ${ }^{b}$ Junta Central de Usuarios del Vinalopó, L' Alacantí y Consorcio de Aguas de la Marina Baja (Aspe, Alicante; vicente@ juntacentral.es)

\section{Resumen}

El sistema de explotación Vinalopó-Alacantí, localizado al sur de la Demarcación Hidrográfica del Júcar, es una importante zona de regadío que se surte principalmente de recursos subterráneos y, al sur del sistema, del Trasvase Tajo-Segura. Para paliar la sobreexplotación de los acuíferos de la zona, el Plan Hidrológico del Júcar de 1998 y el Plan Hidrológico Nacional plantearon la sustitución de bombeos por recursos superficiales del río Júcar a través de la Conducción Júcar-Vinalopó, lo que supone duplicar o triplicar, según zonas, el coste del agua para riego, resultando en la inoperatividad, hasta la fecha, de la infraestructura. En este trabajo se evalúa el impacto económico sobre el regadío del Vinalopó-Alacantí de la sustitución de recursos subterráneos por los provenientes del río Júcar. Para ello, se ha utilizado un modelo agro-económico calibrado en base a la asignación real de cultivos de la zona. Los resultados muestran una reducción de la demanda de agua y la superficie regada de más de un 35\%, afectando principalmente a cultivos extensivos, viñedo para vinificación, olivar, cítricos y algunos hortícolas. Asimismo, el impacto económico no se repartiría homogéneamente, sino que sería especialmente severo en los regadíos del Alto Vinalopó y del Pinós y Albatera.

\section{Palabras clave}

Trasvases inter-cuencas, sobreexplotación de acuíferos, modelos agro-económicos, demanda de agua

\section{Introducción y objetivos}

El sistema de explotación Vinalopó-Alacantí (SEVA) está localizado al sur de la Demarcación Hidrográfica del Júcar. Se trata de una cuenca hidrográfica con una extensión total de $2,786 \mathrm{~km}^{2}$ y que incluye territorio de la Comunidad Valenciana, Castilla-La Mancha y la Región de Murcia. En el SEVA coexisten una importante agricultura de regadío con una elevada población residente y una importante actividad turística concentrada en la costa Sur de la provincia de Alicante. Esto genera una situación de competencia por los recursos hídricos entre los usos urbanos y los agrarios que suponen aproximadamente un $40 \%$ y un 55\% del consumo de agua respectivamente.

La principal fuente de suministro de agua en la zona son las aguas subterráneas provenientes de diferentes acuíferos, la mayoría de ellos sobreexplotados. Para el conjunto del SEVA, se estima un consumo de 113 $\mathrm{hm}^{3}$ anuales de aguas subterráneas, con una recarga media anual estimada en $48 \mathrm{hm}^{3}$, lo que supone una sobreexplotación equivalente a $65 \mathrm{hm}^{3} /$ año de extracciones no renovables que se constituye como uno de los principales problemas medioambientales de la zona.

El Plan Hidrológico de la Demarcación Hidrográfica del Júcar de 1998 [CHJ (1998)], y derivado de ello el Plan Hidrológico Nacional [MIMAM (2001)], planteó la sustitución de bombeos por recursos superficiales del río Júcar, trasvasados a través de la Conducción Júcar-Vinalopó, como una de las soluciones para paliar la sobreexplotación de acuíferos en la zona. En su concepción inicial, la toma del trasvase en el Río Júcar se situaba en Cortes de Pallás y contemplaba que los recursos trasvasados se destinasen tanto a usos urbanos como de regadío. Finalmente, la toma del trasvase se situó cerca de la desembocadura del río Júcar, donde la calidad del agua es significativamente peor, por lo que el destino de los recursos a trasvasar se limitaría al regadío.

El regadío en el SEVA incluye tanto una importante producción hortofrutícola, en la que destacan cultivos como la uva de mesa (amparada por una Denominación de Origen Protegida), el viñedo para vinificación, el granado, los cítricos y los hortícolas protegidos, como cultivos extensivos (principalmente cereales) y una importante superficie de olivar y almendro.

La superficie de regadío actual abarca 40.674 hectáreas [CHJ (2015)] que se reparten entre diez Unidades de Demanda Agraria (UDA) que se nutren de recursos hídricos de diferentes orígenes entre los que se incluyen los subterráneos, el Acueducto Tajo-Segura (ATS), la reutilización de aguas residuales urbanas y una mínima aportación de recursos superficiales (Cuadro 1). Según el plan hidrológico del Júcar [CHJ 
(2015)], la disponibilidad media de recursos hídricos para el regadío del SEVA asciende a 147,42 hm³/año en alta (Cuadro 1).

En cuanto al coste de los recursos hídricos, el coste medio en alta en cada UDA depende del mix de recursos hídricos utilizados y del coste de bombeo en cada zona, el cual oscila entre 0,094 y $0,191 € / \mathrm{m}^{3}$, con un valor medio para el SEVA de $0,156 € / \mathrm{m}^{3}$. La substitución de recursos subterráneos por recursos del Júcar supondría duplicar o triplicar, según zonas, el coste del agua para riego, lo que ha supuesto, hasta la fecha, la inoperatividad de la infraestructura. En este sentido, el objetivo de este estudio es evaluar el impacto económico sobre la agricultura de regadío del Vinalopó-Alacantí de la sustitución de recursos subterráneos por los no convencionales transferidos a través de la Conducción Júcar-Vinalopó.

Cuadro 1. Superficie neta regada y disponibilidad media del agua en las UDAs del SEVA

\begin{tabular}{|c|c|c|c|c|c|}
\hline \multirow[b]{2}{*}{$\begin{array}{l}\text { Unidad de Demanda Agraria } \\
\text { (UDA) }\end{array}$} & \multirow[b]{2}{*}{$\begin{array}{l}\text { Superficie } \\
\text { neta (ha) }\end{array}$} & \multicolumn{4}{|c|}{ Disponibilidad media de agua (hm³/año en alta) } \\
\hline & & Superficial & $\begin{array}{l}\text { Subterrán } \\
\text { ea }\end{array}$ & $\begin{array}{l}\text { Reutilizad } \\
\text { a }\end{array}$ & $\begin{array}{c}\text { Tajo- } \\
\text { Segura }\end{array}$ \\
\hline $\begin{array}{l}\text { UDA 082070A: Riegos de la } \\
\text { cabecera del Monnegre }\end{array}$ & 1148 & 0,35 & 3,20 & 0,04 & 0,00 \\
\hline UDA 082071A: Riegos del Jijona & 502 & 0,66 & 1,09 & 0,00 & 0,00 \\
\hline $\begin{array}{l}\text { UDA 082072A: Riegos de Levante } \\
\text { MI: Huerta de Alicante y Bacarot }\end{array}$ & 1127 & 0,79 & 0,00 & 1,03 & 5,74 \\
\hline $\begin{array}{l}\text { UDA 082073A: Riegos del } \\
\text { Alacantí }\end{array}$ & 4597 & 0,07 & 13,03 & 6,63 & 0,00 \\
\hline $\begin{array}{l}\text { UDA 082074A: Riegos mixtos del } \\
\text { Alto Vinalopó }\end{array}$ & 751 & 1,25 & 0,57 & 0,00 & 0,00 \\
\hline $\begin{array}{l}\text { UDA 082075A: Riegos } \\
\text { subterráneos del Alto Vinalopó }\end{array}$ & 10097 & 0,30 & 30,06 & 2,60 & 0,00 \\
\hline $\begin{array}{l}\text { UDA 082076A: Riegos del Medio } \\
\text { Vinalopó }\end{array}$ & 9424 & 0,50 & 27,50 & 1,71 & 0,00 \\
\hline $\begin{array}{l}\text { UDA 082077A: Riegos del Bajo } \\
\text { Vinalopó }\end{array}$ & 1428 & 0,05 & 4,97 & 0,31 & 1,63 \\
\hline $\begin{array}{l}\text { UDA 092001A: Riegos de Levante } \\
\text { MI: Camp d'Elx }\end{array}$ & 7458 & 0,00 & 0,00 & 10,93 & 28,17 \\
\hline $\begin{array}{l}\text { UDA 092002A: Riegos del Pinos y } \\
\text { Albatera }\end{array}$ & 4142 & 0,00 & 4,24 & 0,00 & 0,00 \\
\hline TOTAL & 40674 & 3,97 & 84,66 & 23,25 & 35,54 \\
\hline
\end{tabular}

Fuente: Elaboración propia con datos de CHJ (2015) y CHJ (2019)

\section{Metodología}

El impacto económico sobre el regadío del Vinalopó-Alacantí de las alternativas analizadas se ha evaluado utilizando un modelo no-lineal de optimización que simula las decisiones de asignación de tierra y agua entre los cultivos de regadío de cada una de las diez Unidades de Demanda Agraria (UDA) de la zona de estudio y genera indicadores económicos de uso del agua. La estructura de dicho modelo agro-económico es la del modelo descrito en Calatrava y Martínez-Granados (2019), pero todos sus parámetros técnicos y económicos han sido adaptados a las características de la zona de estudio. El modelo ha sido calibrado utilizando el enfoque de calibración mediante Programación Matemática Positiva propuesto por Gohin y Chantreuil (1999).

El modelo calibrado se ha utilizado para simular y evaluar dos escenarios:

- Escenario 1: Situación actual de disponibilidad de recursos hídricos y coste de dichos recursos, de acuerdo con lo establecido en CHJ (2015);

- Escenario 2: Sustitución de bombeos de los acuíferos del Subsistema por recursos del trasvase Júcar-Vinalopó, considerando un coste de suministro en alta a soportar por los regantes de 0,31 $€ / \mathrm{m}^{3}$, de acuerdo con lo establecido en el escenario 2 de sustitución de bombeos definido en CHJ (2015). 


\section{Resultados y discusión}

En el Cuadro 2 se muestra la variación porcentual de los resultados generados por el modelo para el escenario 2 con respecto a los obtenidos para el escenario actual. El Cuadro 2 muestra, en primer lugar, como las UDAs que no recibirían recursos del TJV no se verían obviamente afectadas en este segundo escenario. En el caso de las UDAs afectadas por el TJV, el escenario 2 de sustitución de bombeos analizado reduciría la demanda de agua en un $34,5 \%$ con respecto a la situación actual como consecuencia del incremento del coste de suministro del agua de riego. Esta reducción en el uso de recursos hídricos causaría, en el conjunto de las 6 UDAs afectadas por el TJV, una reducción del 36,7\% en la superficie media regada (10.215 hectáreas menos), del 14,6\% en la producción agraria (49,4 millones de euros/año menos), del 10\% en el margen neto de las explotaciones ( 8,2 millones de euros/año menos) y del 13,4\% en el empleo agrario (935 UTAs anuales menos).

La reducción de la superficie regada, aunque afecta a la mayoría de los cultivos en mayor o menos medida, corresponde principalmente a cultivos extensivos (cereales, forrajeros, leguminosas), el viñedo para vinificación, el olivar y los cítricos, aunque también afecta significativamente, aunque en porcentajes menores, a frutales como el granado y hortícolas como la zanahoria, la alcachofa, el puerro e incluso a la lechuga. El incremento que se observa en el valor marginal de uso del agua de riego (Cuadro 2) se debe a la reducción de la superficie cultivada y la demanda de agua como consecuencia del incremento del coste del agua de riego.

Asimismo, el impacto económico negativo del incremento del coste del agua no sería homogéneo en toda la zona (Cuadro 2). Mientras que en los Riegos del Alacantí y en los Riegos mixtos del Alto Vinalopó el impacto económico sería más limitado, en los Riegos del Medio Vinalopó y del Bajo Vinalopó sería mayor debido a una reducción de la superficie regada de aproximadamente un tercio de la actual. El impacto económico sería especialmente grave en el caso de los Riegos subterráneos del Alto Vinalopó y en los Riegos del Pinós y Albatera debido a una reducción de la superficie regada que supera con creces el 50\%.

Cuadro 2. Variación porcentual de los resultados del modelo agro-económico en el escenario de trasvase Júcar-Vinalopó con respecto de la situación actual

\begin{tabular}{lcccccc}
\hline \multicolumn{1}{c}{ UDA/ZONA } & $\begin{array}{c}\text { Agua } \\
\text { utilizada }\end{array}$ & $\begin{array}{c}\text { Valor } \\
\text { marginal } \\
\text { del agua }\end{array}$ & $\begin{array}{c}\text { Valor de la } \\
\text { producción } \\
\text { agraria }\end{array}$ & $\begin{array}{c}\text { Margen } \\
\text { neto de } \\
\text { explotación }\end{array}$ & $\begin{array}{c}\text { Superficie } \\
\text { regada }\end{array}$ & $\begin{array}{c}\text { Mano de } \\
\text { obra } \\
\text { utilizada }\end{array}$ \\
\hline $082073 \mathrm{~A}$ & $-4,11 \%$ & $20,00 \%$ & $-1,09 \%$ & $-0,90 \%$ & $-3,01 \%$ & $-0,74 \%$ \\
$082074 \mathrm{~A}$ & $-10,17 \%$ & $15,38 \%$ & $0,70 \%$ & $-0,36 \%$ & $-6,66 \%$ & $2,73 \%$ \\
082075A & $-47,79 \%$ & $92,86 \%$ & $-32,97 \%$ & $-17,55 \%$ & $-55,10 \%$ & $-36,12 \%$ \\
082076A & $-35,87 \%$ & $93,75 \%$ & $-14,64 \%$ & $-9,67 \%$ & $-32,70 \%$ & $-13,62 \%$ \\
082077A & $-35,75 \%$ & $93,75 \%$ & $-11,72 \%$ & $-14,82 \%$ & $-32,66 \%$ & $-7,53 \%$ \\
092002A & $-51,13 \%$ & $121,43 \%$ & $-38,33 \%$ & $-31,13 \%$ & $-60,44 \%$ & $-37,97 \%$ \\
$\begin{array}{l}\text { Subtotal UDAS } \\
\text { del TJV }\end{array}$ & $\mathbf{- 3 4 , 5 6 \%}$ & $\mathbf{6 6 , 6 7 \%}$ & $\mathbf{- 1 4 , 6 4 \%}$ & $\mathbf{- 9 , 9 7 \%}$ & $\mathbf{- 3 6 , 7 3 \%}$ & $\mathbf{- 1 3 , 4 4 \%}$ \\
\hline $\begin{array}{l}\text { Subtotal resto } \\
\text { de UDAs }\end{array}$ & $\mathbf{0 , 0 0 \%}$ & $\mathbf{0 , 0 0 \%}$ & $\mathbf{0 , 0 0 \%}$ & $\mathbf{0 , 0 0 \%}$ & $\mathbf{0 , 0 0 \%}$ & $\mathbf{0 , 0 0 \%}$ \\
\hline $\begin{array}{l}\text { TOTAL } \\
\text { SUBSISTEMA }\end{array}$ & $\mathbf{- 2 2 , 3 4 \%}$ & $\mathbf{4 6 , 1 5 \%}$ & $\mathbf{- 8 , 9 4 \%}$ & $\mathbf{- 6 , 0 9 \%}$ & $\mathbf{- 2 6 , 8 5 \%}$ & $\mathbf{- 8 , 1 0 \%}$ \\
\hline
\end{tabular}

Nota: Agua en alta. Denominación de las UDAs: 082073A: Riegos del Alacantí; 082074A: Riegos mixtos del Alto Vinalopó; 082075A: Riegos subterráneos del Alto Vinalopó; 082076A: Riegos del Medio Vinalopó; 082077A: Riegos del Bajo Vinalopó; 092002A: Riegos del Pinós y Albatera.

Fuente: Elaboración propia.

\section{Conclusiones}

Los resultados obtenidos para el conjunto de las seis UDAs afectadas por la sustitución de bombeos por recursos del trasvase Júcar-Vinalopó, muestran como el incremento del coste de suministro del agua resultante reducirían la demanda de agua y la superficie regada en más de un tercio con respecto a la situación actual. Los cultivos más afectados serían los cultivos extensivos, el viñedo para vinificación, el olivar y los cítricos, aunque también afectaría de manera significativa a algunos frutales y cultivos hortícolas. El impacto económico previsto (una caída del 14,6\% en la producción agraria y del 13,4\% en el empleo agrario) no se repartiría de manera homogénea, sino que sería especialmente grave en los regadíos 
de aguas subterráneas del Alto Vinalopó y del Pinós y Albatera y, en menor medida, en los regadíos del Medio y Bajo Vinalopó, siendo más reducido en el Alacantí y en los regadíos mixtos del Alto Vinalopó.

Algunas de las posibles alternativas que permitirían reducir el coste de los recursos provenientes del Júcar y, por lo tanto, reducir su impacto económico sobre el regadío serían la integración de la generación fotovoltaica en el sistema para reducir el coste energético del TJV, y la contribución de los usos urbanos a los sobrecostes que el TJV supone. En su concepción inicial, el trasvase Júcar-Vinalopó se planteaba para el suministro tanto urbano como agrario, aunque los cambios en el proyecto limitaron los usos de los recursos a trasvasar a los de regadío. Sin embargo, los usos urbanos se beneficiarían de manera indirecta del TJV debido a la recuperación de los acuíferos que éste permitiría. Ambas cuestiones son objeto de estudio en la actualidad.

\section{Agradecimientos}

La realización de este trabajo ha sido posible gracias a la financiación proporcionada por la Fundación PRIMA a través del proyecto WATERMED 4.0 (Proyecto número 1821).

\section{Bibliografía}

Calatrava, J. y Martínez-Granados, D. (2019). "Water buybacks to recover depleted aquifers in south-east Spain". International Journal of Water Resources Development, 35(6): 977-998.

CHJ (1998). Plan Hidrológico de cuenca del Júcar. Confederación Hidrográfica del Júcar, Valencia.

CHJ (2015). Plan Hidrológico de la Demarcación Hidrográfica del Júcar. Ciclo de planificación hidrológica 2015-2021. Confederación Hidrográfica del Júcar, Valencia.

CHJ (2019). Documentos iniciales del tercer ciclo de planificación hidrológica (2021-2027). Confederación Hidrográfica del Júcar, Valencia.

Gohin, A. y Chantreuil, F. (1999). "La programmation mathématique dans les modèles d'exploitation agricole. Principes et importance du calibrage". Cahiers d'Économie et Sociologie Rurales, 52:5977.

MIMAM (2001). Plan Hidrológico Nacional. Ministerio de Medio Ambiente: Madrid. 